\title{
The Constants in the Equation for Atmospheric Refractive Index at Radio Frequencies
}

\author{
Ernest K. Smith, Jr., and Stanley Weintraub
}

\begin{abstract}
Recent improvements in microwave techniques have resulted in precise measurements at the National Bureau of Standards, the National Physical Laboratory, and elsewhere, which indicate that the conventional constants $K_{1}=79^{\circ} \mathrm{K} / \mathrm{mb}$ and $K_{2}{ }^{\prime}=4,800^{\circ} K$ in the expression for the refractivity of air, $N=(n-1) 10^{6}=\left(K_{1} / T\right)\left[p+K_{2}^{\prime}(e / T)\right]$ should be revised. Various laboratories appear to have arrived at this conclusion independently, with the result that there are several different sets of constants in eurrent use. In much of propagation work the absolute value of the refractive index of the atmosphere is of small moment. However, in some work it is important, and it seems highly desin able to decide upon a particular set of constants.

Through consideration of the various recent experiments a relation $N=(77.6 / T)[p+4810$ $(e / T)$ ] is derived, where $p$ is the total pressure, in millibars, $e$ is the partial pressure of water vapor, in millibars, and $T$ is absolute temperature $\left({ }^{\circ} \mathrm{C}+273\right)$. This expression is considered to be good to 0.5 percent in $N$ for frequencies up to 30,000 megacycles and normally encountered ranges of temperature, pressure, and humidity.
\end{abstract}

Recent improvements in microwave techniques have resulted in measurements at the National Bureau of Standards [1], ${ }^{1}$ the National Physical Laboratory [2], and elsewhere [3, 4, 5], which have indicated that the conventional constants in the expression for the refractive index of air at radio frequencies should be revised. Various laboratories appear to have arrived at this conclusion independently, with the result that there are several different sets of constants in current use $[6,7,8,9]$. The sources of these recent changes, such as have been run to earth, have been found to be based on individual rather than collective results. Almost all the proposed constants seem to represent a substantial improvement over the former values. The authors propose a set of constants derived from what is felt to be the most reliable of the recent microwave and optical measurements of the refractive index of dry air and from a recent survey of water vapor Debye constants. It is hoped that these new constants will provide a common meeting ground for the laboratories desiring change rather than inject just another set of values into the field.

For an accuracy of 0.5 percent in $N$, the scaled-up refractivity of moist air $\left[N=(n-1) 10^{6}\right]$, where $n$ is the refractive index, some simplifying assumptions may be made if the use of the relation is to be restricted to certain limits of the variables. The limits in this case restrict its use to temperatures of -50 to $+40^{\circ} \mathrm{C}$, total pressures of 200 to $1,100 \mathrm{mb}$, water-vapor partial pressures of 0 to $30 \mathrm{mb}$, and a frequency range of 0 to $30,000 \mathrm{Mc}$. The constituents of dry air and even water vapor may be assumed to obey the ideal gas law [10]. The refractive index of water vapor, a polar molecule with an electric dipole, may be represented by a two-term Debye relation [11]. The permeability of air at radio frequencies due to oxygen may be taken as $1+0.4 \times 10^{-6}$ [1]. Dispersion may be neglected. The Lorentz polarization term may be ignored. Absolute zero

Figures in brackets indicate the literature references at the end of this paper. for temperature may be taken as $-273^{\circ} \mathrm{C}$ rather than $-273.16^{\circ} \mathrm{C}[12]$.

There has been no proof of variation in the composition of the dry gases of the free atmosphere either with latitude or with height up to the ionosphere [13]. The water vapor content, of course, varies widely. As contributions to the total refractive index obey an additive rule, a three-term expression may be formulated [11], in which the first term expresses the sum of the distortions of electronic charges of the dry-gas molecules under the influence of an applied electromagnetic field; the second term, these distortions for water vapor; and the third term, the effect of the orientation of the electric dipoles of water vapor under the influence of a field. Thus, using $N$ for the scaled-up refractivity $\left[N=(n-1) 10^{6}\right]$,

$$
N=K_{1}\left(\frac{P_{d}}{T}\right)+K_{2}\left(\frac{e}{T}\right)+K_{3}\left(\frac{e}{T^{2}}\right)
$$

where $n$ is the refractive index at radio frequencies; $P_{d}$, the partial pressure of the dry gases; $e$, the partial pressure of water vapor; and $T$, the absolute temperature.

In radio work one is interested in propagation through the free atmosphere. Therefore, the composition of air should be taken to include an average amount of carbon dioxide. However, laboratory measurements usually are made on $\mathrm{CO}_{2}$-free air because of variable concentrations of $\mathrm{CO}_{2}$ in the laboratory. Hence, those values of $\epsilon-1$ originally published for $\mathrm{CO}_{2}$-free air have been adjusted for 0.03 percent $\mathrm{CO}_{2}$ content by raising them 0.02 percent. These values are also given on a real rather than an ideal gas basis. Three determinations shown in table 1 are considered. The first shown, that of Barrell [14], is an average of the constant term ( $n$ for $\lambda=\infty$ ) of the optical Cauchy dispersion equations for standard air used in three of the principal metrology laboratories of the world. Theoretical considerations indicate that the dielectric constant 
for dry air will be the ${ }_{i}$ same for optical and radio frequencies. Barrell's value is converted to dielectric constant from the relation $n=\sqrt{\mu \epsilon}$ with $\mu$, the permeability, taken as unity at optical frequencies. The second value, that of Birnbaum, Kryder, and Lyons [1] ,was originally published on an ideal basis but has here been converted to the value pertinent to real gases. The last determination, that of Essen and Froome [2], has been adjusted to include $\mathrm{CO}_{2}$. The uncertainties listed are standard errors.

TABLE 1. Dry-air refractive index and dielectric constant at $0^{\circ} \mathrm{C}$ and 1 atmosphere

\begin{tabular}{|c|c|c|c|c|}
\hline & $\begin{array}{l}\text { Frequency } \\
\text { of measure- } \\
\text { ment }\end{array}$ & Measured $N$ & $(\epsilon-1) 10^{6}$ & Year \\
\hline $\begin{array}{l}\text { Barrell [14] } \\
\text { Birnbaum, Kryder }\end{array}$ & $\begin{array}{l}\text { Optical } \\
9,000 \mathrm{Me}\end{array}$ & $287.7_{6} \pm 0.065$ & $\begin{array}{l}575.6 \pm 0.1_{3} \\
575.8 \pm 0.3_{6}\end{array}$ & $\begin{array}{l}1951 \\
1951\end{array}$ \\
\hline $\begin{array}{l}\text { Essen and Froome } \\
{[2] \text {. }}\end{array}$ & $24,000 \mathrm{Mc}_{\ldots} \ldots$ & $288.2 \pm \pm 0.1$ & $576.1 \pm 0.2$ & 1951 \\
\hline \multicolumn{2}{|l|}{ Mean value.. } & a $288.0_{4} \pm 0.0_{5}$ & $575.7_{5} \pm 0.1_{0}$ & \\
\hline
\end{tabular}

a Derived from $n=\sqrt{\mu \epsilon}$, where $\mu-1=0.4 \times 10^{-6}$ is taken for radio frequencies to account for the permeability.

The statistical mean value of dielectric constant is then converted to refractive index. The constant $K_{1}$ is evaluated from

$$
N=K_{1} \frac{p_{d}}{T}
$$

which stems from (1) when $\ell=0$. Setting $N=288.04$, $p=1013.25 \mathrm{mb}, T=273^{\circ} \mathrm{C}$ and solving for $K_{1}$ :

$$
K_{1}=77.60_{7} \pm 0.01_{3} \frac{{ }^{\circ} \mathrm{K}}{\mathrm{mb}}
$$

A recent survey of determinations of the dielectric constant of water vapor in the microwave region by Birnbaum and Chatterjee [15] is used to evaluate the water-vapor constants $K_{2}$ and $K_{3}$ in (1). Assuming ideal gas behavior, which is permissible here as only low partial pressures are of interest, the constants may be evaluated from the Debye constants $A$ and $B$ (molar polarization $P=A+B / T$ ) determined by Birnbaum and Chatterjee. This results in

$$
\begin{gathered}
K_{2}=71_{.6} \pm 8 \cdot 5 \frac{{ }^{\circ} \mathrm{K}}{\mathrm{mb}} \\
K_{3}=\left(3.74_{7} \pm 0.03_{1}\right) 10^{5} \frac{{ }^{\circ} \mathrm{K}^{2}}{\mathrm{mb}}
\end{gathered}
$$

where the uncertainties are again standard errors. Substituting the values of (3), (4), and (5) in (1), and reducing the values to three figures where significant

$$
N=77.6 \frac{p_{d}}{T}+72 \frac{e}{T}+3.75 \times 10^{5} \frac{e}{T^{2}} .
$$

Utilizing the total pressure, $p=P_{d}+e$, one may write

$$
N=77.6 \frac{p}{T}-6 \frac{e}{T}+3.75 \times 10^{5} \frac{e}{T^{2}} .
$$

For use in the limited temperature range $-50^{\circ}$ to $+40^{\circ} \mathrm{C}$, negligible error is incurred through lumping the second and third terms in (7). This may be accomplished by dividing these terms by $e / T$ and solving for the composite constant, $K_{4}$, in the relation

$$
\frac{3.75 \times 10^{5}}{T}-6=\frac{K_{4}}{T}
$$

which, for $T=273^{\circ} \mathrm{K}$, results in

$$
K_{4}=3.73 \times 10^{5} \text {. }
$$

The two-term formula for dry air is now

$$
N=77.6 \frac{p}{T}+3.73 \times 10^{5} \frac{e}{T^{2}},
$$

which may be written

$$
N=\frac{77.6}{T}\left(p+4.81 \times 10^{3} \frac{e}{T}\right) .
$$

These last two relations are the ones proposed for general radio meteorological use.

Listed in table 2 are some of the values of $K_{1}$, $K_{2}$, and $K_{3}$, that have been used by authors through the years. In examples 1 through 7 the constant $K_{1}$ was drawn from the Smithsonian Physical Tables (1933). The water-vapor constants $\dot{K}_{2}$ and $K_{3}$ in examples 2 to 7 represent an average of the determinations of several different workers in each case. Essen and Froome in example 8 relied on their own

\begin{tabular}{|c|c|c|c|c|}
\hline Author & Year & $K_{1}$ & $K_{2}$ & $K_{3}$ \\
\hline $\begin{array}{l}\text { 1. Schelleng, Burrows, and } \\
\text { Ferrell [16] } \\
\text { 2. Englund, Crawford, and } \\
\text { Mumford [17] } \\
\text { 3. Waynick [18] } \\
\text { 4. Smith-Rose and Stickland } \\
\text { [19] } \\
\text { 5. NDRC, Burrows and Att- } \\
\text { wood [20] } \\
\text { 6. Meteorological Factors in } \\
\text { Propagation [21] } \\
\text { 7. Radiation Laboratory, vol. } \\
\text { 13 (Kerr) [11] } \\
\text { 8. Essen and Froome [2] } \\
\text { 9. Smith and Weintraub.... }\end{array}$ & $\begin{array}{l}1933 \\
1935 \\
1940 \\
1943 \\
1946 \\
1946 \\
1951 \\
1951 \\
1952\end{array}$ & $\begin{array}{l}79 \\
79.1 \\
79 \\
79 \\
79 \\
79 \\
79 \\
77.64 \\
77.6\end{array}$ & $\begin{array}{l}675 \\
68.3 \\
68.5 \\
68 \\
68 \\
68 \\
(79) \\
64.68 \\
72\end{array}$ & $\begin{array}{l}1.35 \times 10^{5} \\
3.81 \\
3.72 \\
3.77 \\
3.8 \\
3.8 \\
3.8 \\
3.718 \\
3.75\end{array}$ \\
\hline
\end{tabular}
excellent experimental work to evaluate $K_{1}$ and $K_{3}$. Their value of $K_{1}$ is seen from table 1 to be in excellent agreement with the values of Barrell and of Birnbaum, Kryder, and Lyons. However, their value for $K_{3}$ is low because of the fact that their measured value of the dielectric constant of water vapor is about 1 percent lower than those determined

TABLE 2. Constants used by different authors

$$
N=(n-1) 10^{6}=K_{1} \frac{p}{T}+K_{2} \frac{e}{T}+K_{3} \frac{e}{T^{2}}
$$


by other recent workers in the field. It is true that their measurements were performed in a region adjacent to the $1.35-\mathrm{cm}$ water-vapor absorption band, but this effect has been shown to be too small to account for the discrepancy. As Essen and Froome did not have refractive-index determinations over the wide temperature range necessary to evaluate $K_{2}$ and $K_{3}$ independently, they utilized an optical value of refractive index $\left(K_{3}=0\right)$ to determine $K_{2}$. Consequently, their value for $K_{2}$ is about 10 percent low at radio frequencies. However, the effect of this on the equation is negligible.

The authors thank George Birnbaum, Arthur Maryott, Jack W. Herbstreit, and Kenneth A. Norton for their advice and assistance in this work.

\section{References}

[1] G. Birnbaum, S. J. Kryder, and H. Lyons, J. Applied Phys. 22, 95 (1951).

[2] L. Essen and K. D. Froome, Proc. Phys. Soc. (London) [B] 64, $862(1951)$

[3] C. M. Crain, Phys. Rev. 74, 691 (1948).

[4] W. F. Gabriel, Proc. Inst. Radio Engrs. 40, 940 (Aug. 1952).

[5] W. E. Phillips, Proc. Inst. Radio Engrs. 38, 786 (1950); C. M. Crain, Proc. Inst. Radio Engrs. 40, 164 (Feb. 1952).
[6] C. I. Aslakson and O. O. Fickeissen, Trans. Am. Geophys. Union 31, 819 (1950).

[7] Cornell E. E. Research Interim Engineering Report No. 13, p. 23 (October 27, 1951).

[8] L. Essen and K. D. Froome, Nature 167, 512 (1951)

[9] L. J. Anderson, NEL Report No. 279 (1952).

[10] H. Barrell and J. E. Sears, Philos. Trans. [A] 238, 2 (1940).

[11] Propagation of Short Radio Waves, Edited by D. E. Kerr, Radiation Laboratory Series 13, p. 189 (McGrawHill Book Co., Inc., New York, N. Y., 1951).

[12] ibid. p. 643.

[13] Ionospheric Radio Propagation, NBS Circ. 462, p. 35 (June 1948).

[14] H. Barrell, J. Optical Soc. Am. 41, 295 (1951).

[15] G. Birnbaum and S. K. Chatterjee, J. Applied Phys. 23, 220 (Feb. 1952).

[16] J. C. Schelleng, C. R. Burrows, and E. B. Ferrell, Proc. Inst. Radio Engrs. 21, 427 (1933).

[17] C. R. Englund, A. B. Crawford, and W. W. Mumford, Bell System Tech. J. 14, 369 (1935).

[18] A. H. Waynick, Proc. Inst. Radio Engrs. 28, 468 (1940).

[19] R. L. Smith-Rose and A. C. Stickland, J. Inst. Elec. Engrs. (London) 90, pt. III, 12 (1943).

[20] Radio Wave Propagation, Consolidated Summary Technical Report of the Committee on Propagation, NDRC, Edited by C. R. Burrows and S. S. Attwood (Ácademic Press, Inc., New York, N. Y., 1949), p. 219.

[21] Meteorological Factors in Radio Wave Propagation, Foreword (Phys. Soc., London, 1946).

Boulder, Colo., October 6, 1952. 